\title{
Sevoflurane improves the neuroendocrine stress response during laparoscopic pelvic surgery
}

\section{[Le sévoflurane améliore la réaction neuro-endocrinienne au stress pendant une}

\author{
intervention chirurgicale laparoscopique pelvienne] \\ Elisabetta Marana MD, ${ }^{*}$ Maria Giuseppina Annetta MD, ${ }^{*}$ Francesco Meo MD, ${ }^{*}$ Raffaella Parpaglioni MD, * \\ Marina Galeone MD, ${ }^{*}$ Maria Luisa Maussier MD, $†$ Riccardo Marana MD $\ddagger$
}

Purpose: Stress response to surgery is modulated by several factors, including magnitude of the injury, type of procedure (e.g., laparoscopy vs laparotomy) and type of anesthesia. Our purpose was to compare intra- and postoperative hormonal changes during isoflurane vs sevoflurane anesthesia, in a clinical model of well defined operative stress (laparoscopic pelvic surgery).

Method: In this prospective randomized clinical study, 20 women requiring laparoscopic pelvic surgery for benign ovarian cysts received either a standard isoflurane plus fentanyl (Group A) or sevoflurane plus fentanyl anesthesia (Group B). Blood samples were collected preoperatively, $30 \mathrm{~min}$ after the beginning of surgery, at the end of surgery after extubation, and two and four hours after the end of surgery. Intra- and postoperative plasma levels of norepinephrine, epinephrine, adrenocorticotropic hormone (ACTH), cortisol, growth hormone $(\mathrm{GH})$ and prolactin $(\mathrm{PRL})$ were measured.

Results: Catecholamine levels and postoperative pain were similar in both groups. Nonetheless, in comparison to Group A, Group B showed a significant decrease of $A C T H$, cortisol and $G H$ levels ( $A$ vs $B$ at the end of surgery: ACTH $160 \pm 45$ vs $100 \pm 40 \mathrm{pg} \cdot \mathrm{mL}^{-1}$; cortisol $45 \pm 8$ vs $23 \pm 7 \mu \mathrm{g} \cdot \mathrm{dL}^{-1} ; \mathrm{GH} 3 \pm 2$ vs $0.8 \pm 0.4$ $\mathrm{ng} \cdot \mathrm{mL}^{-1} ; P<0.00$ I for all), but enhanced PRL levels (A vs B, at 30 min after the beginning of surgery: $139 \pm 54 \mathrm{vs} \mid 85 \pm 22 \mathrm{ng} \cdot \mathrm{mL}^{-1}$; at the end of surgery: $100 \pm 27 \mathrm{vs}|4| \pm 45 \mathrm{ng} \cdot \mathrm{mL}^{-1} ; P<0.00$ । for both).

Conclusions: In the clinical setting of low stress laparoscopic surgery, the type of volatile anesthetic significantly affected the stress response; the changes associated with sevoflurane suggested a more favourable metabolic and immune response compared to isoflurane.
Objectif : La réaction au stress chirurgical dépend, entre autres, de l'importance du traumatisme chirurgical, du type d'intervention (laparoscopie vs laparotomie) et d'anesthésie. Nous voulions comparer les changements hormonaux pendant et après l'opération sous anesthésie à l'isoflurane, ou au sévoflurane, selon un modèle clinique bien défini de stress opératoire (intervention chirurgicale par laparoscopie pelvienne).

Méthode : L'étude clinique, prospective et randomisée, a été faite auprès de 20 femmes devant subir une intervention par laparoscopie pelvienne pour des kystes bénins de l'ovaire. Les patientes ont reçu, soit une anesthésie normale à l'isoflurane avec du fentanyl (groupe A), soit au sévoflurane avec du fentanyl (groupe B). Le sang a été prélevé avant l'opération, 30 min après le début, à la fin après l'extubation et, deux et quatre heures après l'opération. Les niveaux plasmatiques peropératoire et postopératoire de noradrénaline, d'adrénaline, d'hormone adrénocorticotrope (ACTH), de cortisol, d'hormone de croissance $(G H)$ et de prolactine (PRL) ont été mesurés.

Résultats : Les niveaux de catécholamine et la douleur postopératoire ont été similaires dans les deux groupes. Néanmoins, comparé au groupe $A$, le groupe $B$ a affiché une baisse significative d'ACTH, de cortisol et de GH (A vs B à la fin de l'opération: ACTH $160 \pm 45$ vs $100 \pm 40 \mathrm{pg} \cdot \mathrm{mL}^{-1}$; cortisol $45 \pm 8$ vs $23 \pm 7 \mu \mathrm{g} \cdot \mathrm{dL}^{-1} ; \mathrm{GH} 3 \pm 2$ vs $0,8 \pm 0,4 \mathrm{ng} \cdot \mathrm{mL}^{-1} ; P<0,001$ pour toutes), et une hausse de $P R L$ (A vs B, 30 min après le début de l'opération : $139 \pm 54$ vs $185 \pm$ $22 \mathrm{ng} \cdot \mathrm{mL}^{-1}$; à la fin de l'opération: $100 \pm 27 \mathrm{vs} 141 \pm 45 \mathrm{ng} \cdot \mathrm{m}^{-1}$; $P<0,00$ l pour les deux).

Conclusion: Dans le cadre clinique d'une intervention laparoscopique de faible stress, le type d'anesthésique volatil utilisé a un effet significatif sur la réaction de stress; les changements associés au sévoflurane montrent une réaction immunitaire et métabolique plus favorable qu'avec l'isoflurane.

From the Departments of Anesthesiology, Intensive Care and Emergency Medicine, ${ }^{*}$ Nuclear Medicine, $†$ Obstetrics and Gynecology, Catholic University of the Sacred Heart, Rome, Italy.

Address correspondence to: Dr. Maria Giuseppina Annetta, Department of Anesthesiology, Intensive Care and Emergency Medicine,

Catholic University, Largo Francesco Vito 1, I-00168, Rome, Italy. Phone: 39-06-30154507; Fax: 39-06-3013450;

E-mail: mgannetta@tin.it

Supported by research funds of the Department of Anesthesiology.

Accepted for publication July 29, 2002.

Revision accepted December 13, 2002. 


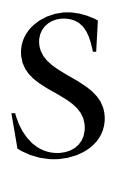

URGICAL procedures are associated with a complex stress response characterized by neurohumoral, immunologic and metabolic alterations.

It has been shown previously that the magnitude of such stress response is proportional to the magnitude of injury, ${ }^{1-4}$ to the total operating time ${ }^{5,6}$ as well as to the amount of intraoperative blood loss ${ }^{7,8}$ and to the degree of postoperative pain; $;{ }^{9} 10$ furthermore, it has been shown that the choice of anesthetic technique may modulate the extent of such response. ${ }^{11-15}$

Decreasing the stress response to surgery and trauma is of high relevance to the anesthesiologist, since it may allow complex operations in high risk patients [American Society of Anesthesiologist (ASA) III-IV, malnourished, immunocompromised and/or elderly) $] ;^{16-18}$ it has been suggested that decreasing operative stress may be a key factor in improving outcome and lowering the length of hospital stay as well as the total costs of patients care. ${ }^{6,19,20}$

Thus, an important goal of current research on new anesthetics is to find the ideal "stress free" anesthetic, to limit the activation of the neuroendocrine, inflammatory and immune responses. ${ }^{21}$ Clinical evidence is accumulating that the choice of the main anesthetic is able to influence the stress response, by stimulating, inhibiting or modulating the pathophysiologic pathways which induce neurohormonal and immunologic alterations. $^{22,15}$

The effect of isoflurane or sevoflurane anesthesia on the modulation of neurohormonal response to surgical trauma remains unclear. Thus, the aim of the present study was to compare the effect of isoflurane or sevoflurane anesthesia on the release of stress hormones, in a selected group of patients undergoing laparoscopic pelvic surgery.

\section{Methods}

Following local Ethical Committee approval and patient informed consent, 20 adult women undergoing benign ovarian cyst surgery by laparoscopy were evaluated prospectively.

All patients were classified as ASA physical status I: we excluded any patient with a history of cardiovascular or nervous system diseases, diabetes, endocrine disorders, obesity (body mass index $>30$ ), previous or current use of medications known to affect the sympathetic response or the hormonal secretion, or drugs/alcohol abuse. The patients were randomized into two study groups according to a computer generated randomization list.

Group A patients $(n=10)$ received an isoflurane based anesthesia, while Group B patients $(n=10)$ received a sevoflurane based anesthesia.
All patients were premedicated with oral diazepam $0.2 \mathrm{mg} \cdot \mathrm{kg}^{-1}, 30 \mathrm{~min}$ before surgery. All operations began between 8:30 a.m. and 9:00 a.m., to minimize variability in the secretion of hormones such as cortisol, which is dependent on circadian rhythm.

All patients received anesthesia according to the following protocol: before induction of anesthesia, patients received $3 \mu \mathrm{g} \cdot \mathrm{kg}^{-1}$ fentanyl, then breathed $100 \% \mathrm{O}_{2}$ for three minutes; anesthesia was induced with $5 \mathrm{mg} \cdot \mathrm{kg}^{-1}$ thiopental; after loss of consciousness, patients received $\mathrm{l}$ minimum alveolar concentration (MAC) either isoflurane (end-tidal concentration $1-1.2 \%$ ) or sevoflurane (end-tidal concentration $1.8-2 \%$ ) in a mixture of $\mathrm{O}_{2} /$ air to obtain $\mathrm{F}_{\mathrm{I}} \mathrm{O}_{2}=0.50$, and the same MAC was maintained during surgery; $0.1 \mathrm{mg} \cdot \mathrm{kg}^{-1}$ vecuronium was used to facilitate endotracheal intubation. The target end-tidal concentrations of inhaled anesthetics were maintained for at least five minutes before the start of the surgical procedure, and maintained during surgery.

Measurement of inspired and end-tidal concentrations of oxygen, carbon dioxide, isoflurane and sevoflurane was performed continuously by infrared spectrometry (Capnomac Ultima, Datex, Helsinki, Finland) calibrated before each anesthetic using a standard gas mixture. Gas samples were collected via a catheter placed at the tracheal end of the endotracheal tube.

All patients were ventilated mechanically to maintain an end-tidal $\mathrm{CO}_{2}$ value between $30-35 \mathrm{mmHg}$. During pneumoperitoneum the intra-abdominal pressure was maintained at $<15 \mathrm{mmHg}$. Skin body temperature was measured at the axilla by a skin temperature probe connected to a Sheridan Sona Temp 400/700 Monitor (Sheridan Catheter Corp, Argyle, NY, USA). Intraoperative monitoring included heart rate (EKG), non-invasive arterial blood pressure (BP), pulse-oximeter, inspired and end-tidal $\mathrm{CO}_{2}$ concentration, inspired and end-tidal isoflurane or sevoflurane concentration.

Maintenance of anesthesia was provided with the respective volatile anesthetic, adjusting the end-tidal concentrations to maintain the patient hemodynamically stable (BP within 15\% of preoperative baseline value and/or heart rate $<85$ beats. $\mathrm{min}^{-1}$ ) during surgical stimulation.

A balanced electrolyte solution (normal saline) was given $i v$ at a constant rate of $6 \mathrm{~mL} \cdot \mathrm{kg}^{-1} \cdot \mathrm{hr}^{-1}$ intraoperatively and $2 \mathrm{~mL} \cdot \mathrm{kg}^{-1} \cdot \mathrm{hr}^{-1}$ postoperatively. Laparoscopic surgery was performed according to standard techniques. ${ }^{23}$ At the last skin suture the inhalated anesthetic was discontinued and the neuromuscular block was reversed.

Patients received ketorolac $30 \mathrm{mg}$ intravenously before the beginning of surgery and ketorolac $30 \mathrm{mg}$ 
iv at the end of the procedure. Ketorolac $30 \mathrm{mg} i v$ was administered every six hours for the first 12 postoperative hours, for postoperative analgesia.

Venous samples were collected peripherally (from an antecubital vein of the arm controlateral to the iv infusion) as follows: at 8:00 a.m. in the ward, at the time of premedication, immediately before transferring the patient to the operating room (time 0 ); 30 min after beginning of operation (time 1 ); at the end of operation after extubation with the patient awake (time 2); and two and four hours after the end of the operation (times 3 and 4 respectively).

Samples were analyzed for concentration of norepinephrine (NE), epinephrine (E), adrenocorticotropic hormone $(\mathrm{ACTH})$, cortisol, growth hormone $(\mathrm{GH})$ and prolactin (PRL).

TABLE I Characteristics of the patient population

\begin{tabular}{llll}
\hline & Group A & Group B & \\
\hline $\begin{array}{l}\text { Age }(\mathrm{yr}) \\
\text { (mean } \pm \text { SD) }\end{array}$ & $33.8 \pm 6.5$ & $32.9 \pm 6.6$ & $\mathrm{NS}$ \\
$\begin{array}{l}\text { Body weight }(\mathrm{kg}) \\
\text { (mean } \pm \text { SD) }\end{array}$ & $55.8 \pm 5.5$ & $57.1 \pm 4.5$ & $\mathrm{NS}$ \\
$\begin{array}{l}\text { Pathology } \\
\text {-serous ovarian cysts }\end{array}$ & 5 & & \\
-mucinous ovarian cysts & 3 & 6 & \\
-endometriotic ovarian cysts & 2 & 1 & \\
Operating time (min) & $55 \pm 16.1$ & $58 \pm 17.9$ & $\mathrm{NS}$ \\
\hline
\end{tabular}

$($ mean $\pm S D)$
The samples were transferred to pre-cooled tubes containing EDTA and $50 \mathrm{~mL}$ glutatione solution, soon centrifugated at $-4^{\circ} \mathrm{C}$, and the plasma was stored at $80^{\circ} \mathrm{C}$ until the analysis. All samples from the same patients were analyzed together within three days of collection. NE and E were measured by high performance liquid chromatography (HPLC) and quantified by electrochemical - coulombmetric method (HPLC EG - ESA 5100A, Coulochem, Bedford, MA, USA). Concentration of ACTH, GH, PRL and cortisol were measured by commercially available radioimmunoassay kits. Interassay and intra-assay coefficient of variability for each assay were as follows: NE 4.6 (inter) and $4 \%$ (intra); E 4.2 and 4\%; ACTH 4.6 and 2.5\%; GH 4.2 and $2.4 \%$; PRL 4 and $2 \%$; cortisol 6.5 and $2.6 \%$.

Postoperatively, at times 3 and 4 , each patient was asked to describe her pain level using a visual analogue scale (VAS), 0 indicating no pain and 10 the worst imaginable pain. The possible occurrence of anesthesia - or surgery-related adverse events was monitored by one of the co-authors.

\section{Statistical analysis}

Differences in stress hormone levels in both groups were analyzed by one way ANOVA and unpaired Student's $t$ test. Paired t test was used to analyze each variable vs baseline level. Differences in VAS score were evaluated by Wilcoxon test. The level of significance was set at $P<0.05$. All results were expressed as mean \pm standard deviation.

TABLE II Hormonal variations during isoflurane anesthesia (Group A)

\begin{tabular}{lllllll}
\hline & $\begin{array}{l}\text { Norepinephrine } \\
p g \cdot m L^{-1}\end{array}$ & $\begin{array}{l}\text { Epinephrine } \\
p g \cdot m L^{-1}\end{array}$ & $\begin{array}{l}\text { ACTH } \\
p g \cdot m L^{-1}\end{array}$ & $\begin{array}{l}\text { Cortisol } \\
\mu g \cdot d L^{-1}\end{array}$ & $\begin{array}{l}\text { Growth hormone } \\
n g \cdot m L^{-1}\end{array}$ & $\begin{array}{l}\text { Prolactin } \\
n g \cdot m L^{-1}\end{array}$ \\
\hline Time 0 & $300 \pm 150$ & $50 \pm 30$ & $45 \pm 27$ & $18 \pm 7$ & $2.2 \pm 1$ & $11.2 \pm 3.4$ \\
Time 1 & $540 \pm 170^{*}$ & $130 \pm 12^{*}$ & $115 \pm 30^{*}$ & $36 \pm 10^{*}$ & $2.8 \pm 0.9$ & $139.4 \pm 54^{*}$ \\
Time 2 & $950 \pm 370^{* *}$ & $180 \pm 90^{*}$ & $160 \pm 45^{*}$ & $45 \pm 8^{*}$ & $3 \pm 2$ & $108 \pm 27.2$ \\
Time 3 & $310 \pm 180$ & $70 \pm 50$ & $50 \pm 18$ & $26 \pm 10$ & $2.2 \pm 0.8$ & $50.6 \pm 18.8^{*}$ \\
Time 4 & $256 \pm 150$ & $100 \pm 78$ & $37 \pm 6$ & $18 \pm 7$ & $2.3 \pm 0.6$ & $30.8_{ \pm 112.9^{*}}$ \\
\hline
\end{tabular}

${ }^{*} P<0.05$ compared to baseline levels; ${ }^{*} P<0.01$.

TABLE III Hormonal variations during sevoflurane anesthesia (Group B)

\begin{tabular}{lllllll}
\hline & $\begin{array}{l}\text { Norepinephrine } \\
\mathrm{gg} \cdot m L^{-1}\end{array}$ & $\begin{array}{l}\text { Epinephrine } \\
\mathrm{pg} \cdot m L^{-1}\end{array}$ & $\begin{array}{l}\text { ACTH } \\
\mathrm{pg} \cdot m L^{-1}\end{array}$ & $\begin{array}{l}\text { Cortisol } \\
\mu g \cdot d L^{-1}\end{array}$ & $\begin{array}{l}\text { Growth hormone } \\
\mathrm{ng} \cdot m L^{-1}\end{array}$ & $\begin{array}{l}\text { Prolactin } \\
\mathrm{ng} \cdot m L^{-1}\end{array}$ \\
\hline Time 0 & $365 \pm 70$ & $56 \pm 25$ & $36 \pm 24$ & $16 \pm 5$ & $1.7 \pm 1.3$ & $14 \pm 9$ \\
Time 1 & $700 \pm 280^{*}$ & $100 \pm 50^{*}$ & $85 \pm 35^{*}$ & $26 \pm 6^{*}$ & $2.5 \pm 0.5^{*}$ & $185 \pm 22^{*}$ \\
Time 2 & $750 \pm 320^{*}$ & $210 \pm 65^{*}$ & $100 \pm 40^{*}$ & $23 \pm 7^{*}$ & $0.8 \pm 0.4$ & $141 \pm 45^{*}$ \\
Time 3 & $300 \pm 140$ & $78 \pm 35$ & $25 \pm 10$ & $12 \pm 8$ & $1.2 \pm 0.4$ & $53 \pm 25^{*}$ \\
Time 4 & $280 \pm 140$ & $75 \pm 40$ & $24 \pm 15$ & $11 \pm 8$ & $0.9 \pm 0.1$ & $60 \pm 31^{*}$ \\
\hline
\end{tabular}

${ }^{*} P<0.05$ compared to baseline levels. 

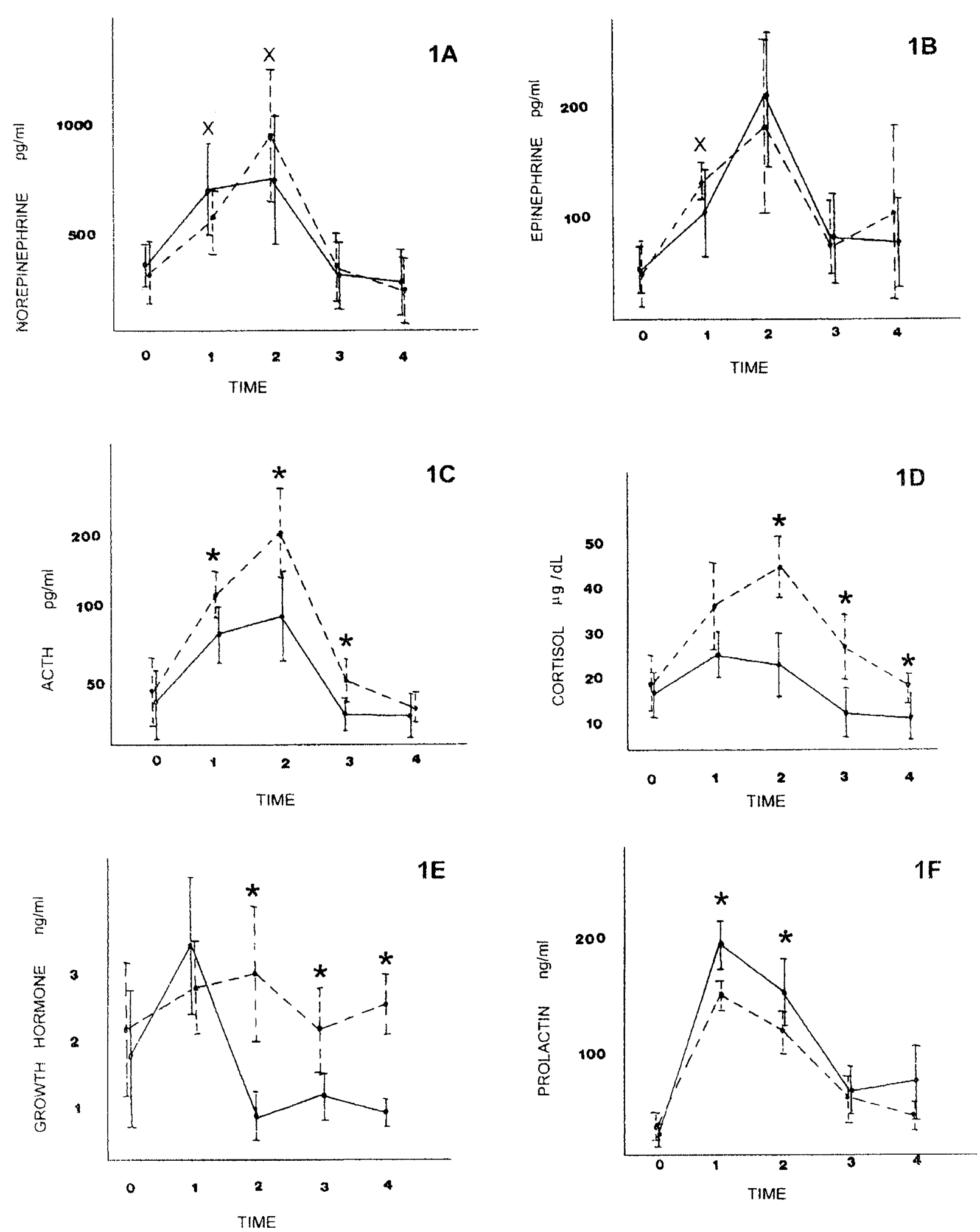

FIGURE Mean serum levels $( \pm \mathrm{SD})$ of norepinephrine $\left(\mathrm{pg} \cdot \mathrm{mL}^{-1} ; \mathrm{lA}\right)$, epinephrine $\left(\mathrm{pg} \cdot \mathrm{mL}^{-1} ; \mathrm{lB}\right), \mathrm{ACTH}\left(\mathrm{pg} \cdot \mathrm{mL}^{-1} ; \mathrm{lC}\right), \mathrm{cortisol}$ $\left(\mu \mathrm{g} \cdot \mathrm{dL}^{-1} ; \mathrm{lD}\right.$, growth hormone $\left(\mathrm{ng} \cdot \mathrm{mL}^{-1} ; \mathrm{lE}\right)$, prolactin $\left(\mathrm{ng} \cdot \mathrm{mL}^{-1} ; \mathrm{lF}\right)$, in sevoflurane group (full line) $v$ isoflurane group (dotted line), at times 0-1-2-3-4. Statistical differences by ANOVA: $\mathrm{X}=P<0.05 ;{ }^{*} P<0.001$. 


\section{Results}

Group A and Group B were similar with regards to mean age, mean body weight and mean operative time (Table I). Patients' age ranged from 22-40 yr, and weight from 50-65 kg. During surgery, there were no significant changes in BP and heart rate, confirming the depth of anesthesia was adequate; in spite of the possible hemodynamic effects of pneumoperitoneum, all variations of $\mathrm{BP}$ and heart rate were no larger than $10 \%$ from baseline. Skin body temperature was constantly between 35.9 and $36.4^{\circ} \mathrm{C}$. No anesthesiologic or surgical complications occurred. No patient required blood transfusion. All patients were discharged on the first postoperative day.

Table II (laparoscopy with isoflurane anesthesia Group A) and Table III (laparoscopy with sevoflurane anesthesia - Group B) show the results of hormonal assays at different operative and postoperative times; a statistical comparison with baseline values is included. Baseline serum levels of all stress hormones evaluated (NE, E, ACTH, cortisol, GH, PRL) were not significantly different between groups. Figure 1 shows an analysis of hormonal fluctuations in both groups.

The degree of pain reported by patients at times 3 and 4 in the two groups was similar and of mild intensity (VAS score: median $=1$, range $1-2$ ).

\section{Discussion}

Few experimental studies have investigated the effects of isoflurane or sevoflurane anesthesia on hormonal and immunological responses. ${ }^{24,25}$ In the present study, we compared isoflurane $v s$ sevoflurane anesthesia, analyzing the variation of serum levels of several stress hormones during and after surgery. We chose a clinical setting (young women undergoing a low stress standardized surgical procedure, i.e., laparoscopy for minor gynecological benign disease) which allowed us to investigate the effects of sevoflurane $v s$ isoflurane, avoiding any interference by other factors which are known to affect hormonal response (age, sex, type and duration of surgery, blood loss, pain, vasoactive drugs, etc.)..$^{8,26-30}$

In this setting, we found that catecholamine levels were relatively unaffected by the choice of the main anesthetic drug: surgical stress caused a similar variation of serum catecholamines both in the isoflurane and in the sevoflurane group. Changes in circulating $\mathrm{E}$ reflect adrenal medullary activity, whereas changes in NE reflect the activity of the overall sympathetic nervous system. ${ }^{31}$ The adrenergic response is related to the extent of surgical trauma and is caused by afferent signals (nociceptive pathways and humoral mediators) originating from the site of injury. ${ }^{32}$ Neither of the anesthetics we tested could apparently inhibit such catecholamine activation.

Things were quite different taking into account the ACTH-cortisol release induced by surgery. ACTH and cortisol are sensitive indicators of stress: plasma increase of ACTH and the subsequent increase of plasma cortisol are known to correlate with the severity of surgical injury. ${ }^{33}$ These hormones cause specific metabolic alterations (the best known is an increase of muscle catabolism, with net negative nitrogen balance), but also affect humoral and cellular immune responses. ${ }^{15}$ The transient immunosuppression induced by the surgical stress might be partially explained by a supranormal activation of the ACTHcortisol axis. It is important to underline that in such clinical conditions both hormones simultaneously increase, because of the loss of the normal pituitaryadrenocortical feed-back mechanisms. ${ }^{34}$ The exact trigger of such adrenocortical response is not completely clear: an important role might be played by some substances directly released at the site of surgery, as well as by cytokines themselves: interleukin- $1 \beta$ and interleukin-6 are important mediators of host defence mechanisms and of the systemic inflammatory response to surgical trauma, and are known to stimulate the release of both ACTH and cortisol. ${ }^{34,35}$

In our study, carried out in a group of controlled, low-stress surgical patients, isoflurane anesthesia was associated with significantly higher concentrations of ACTH and cortisol, when compared to sevoflurane: further studies are needed to confirm this finding in high stress procedures (long, complex, or performed on high-risk, malnourished, and/or immunocompromised patients).

A similar pattern was observed with GH levels, whose increase during surgery was partially inhibited by sevoflurane anesthesia in comparison with isoflurane. $\mathrm{GH}$ is directly released by the hypophysis during the stress response: its metabolic action is in part similar to the one induced by ACTH and cortisol (glyconeogenetic, anti-insulin effect) and in part opposite (anabolic effect with stimulation of protein synthesis in several non-muscle tissues). Its influence on the immune system is still not clear. The potential clinical relevance of the sevoflurane-induced attenuation of GH levels during such low stress procedures is unclear; further studies will investigate this kind of response in 'high stress' surgery.

Stress also causes an increased release of PRL, but the metabolic and immune effects of such increase are less known; PRL is supposed to have an immunostimulatory action which might be potentially beneficial in certain clinical circumstances. ${ }^{36}$ Since PRL 
secretion is mediated by endorphins, its increase during surgery is partially due to fentanyl, which in our study was administrated in all patients at the induction of anesthesia (same dosage in both groups). Though, a significant difference was noticed when comparing sevoflurane with isoflurane: considering the markedly higher levels of PRL during sevoflurane anesthesia $(P$ $<0.001$ ), we may hypothesize a direct pharmacological action of the latter anesthetic on PRL release.

In conclusion, in the clinical setting of a low stress laparoscopic procedure, the use of sevoflurane anesthesia apparently decreases ACTH, cortisol and GH release, but enhances PRL release when compared with isoflurane; although clinical evidence is still lacking, several indirect data suggest that this phenomenon might be associated with a more favourable metabolic and immune response. Further studies are required to verify whether sevoflurane anesthesia might maintain such advantages in more critical surgical procedures on severely ill, immunocompromised and/or malnourished patients.

\section{References}

1 Marana R, Margutti F, Catalano GF, Marana E. Stress response to endoscopic surgery. Curr Opin Obstet Gynecol 2000; 12: 303-7.

2 Cruickshank AM, Fraser WD, Burns HJG, Van Damme $J$, Shenkin A. Response of serum interleukin-6 in patients undergoing elective surgery of varying severity. Clin Sci 1990; 79: 161-5.

3 Naito $\Upsilon$, Tamai S, Shingu K, et al. Response of plasma adrenocorticotropic hormone cortisol and cytokines during and after upper abdominal surgery. Anesthesiology 1992; 77: 426-31.

4 Reith HB, Kaman S, Mittelkötter O, Kilic $\Upsilon$, Kozuschek $W$. Cytokine activation in patients undergoing open or laparoscopic cholecystectomy. Int Surg 1997; 82: 389-93.

5 Karayiannakis AJ, Makri GG, Mantzioka A, Karousos $D$, Karatzas $G$. Systemic stress response after laparoscopic or open cholecystectomy: a randomized trial. $\mathrm{Br}$ J Surg 1997; 84: 467-71.

6 Keblet H, Nielsen HJ. Impact of laparoscopic surgery on stress responses, immunofunction and risk of infections complications. New Horiz 1998; 6(Suppl 2): 80-7.

7 Xin Xu $\Upsilon$, Ayala A, Chaudry IH. Prolonged immunodepression after trauma and hemorrhagic shock. J Trauma 1998; 44: 335-41.

8 Faist E, Angele MK, Zedler S. Immunoregulation in shock, trauma and sepsis. In: "Immune Response in the Critically Ill”. Marshall JC, Cohen J (Eds.). Springer: $2000 ; 312-34$.
9 Keblet $H$. Stress free anesthesia and surgery. Acta Anaesthesiol Scand 1979; 23: 503-4.

10 Keblet $H$. The stress response to surgery: release mechanisms and the modifying effect of pain relief. Acta Chir Scand 1988; 550(Suppl): 22-8.

11 Bent JM, Paterson JL, Mashiter K, Hall GM. Effects of high-dose fentanyl anesthesia on the established and endocrine response to surgery. Anaesthesia 1984; 39: 19-24.

12 Malatinsky J, Vigas M, Jurcovicova I, Jezova D, Garayova S, Minarikova $M$. The patterns of endocrine response to surgical stress during different types of anaesthesia and surgery in man. Acta Anesthesiol Belg 1986; 37: 23-31.

13 Sacerdote P, Bianchi M, Gaspani L, et al. The effects of tramadol and morphine on immune responses and pain after surgery in cancer patients. Anesth Analg 2000; 90: $1411-4$.

14 Hamberger B, Jarnberg PO. Plasma catecholamines during surgical stress. Differences between neurolept and enflurane anaesthesia. Acta Anaesthesiol Scand 1983; 27: 307-10.

15 Kelbel I, Weiss $M$. Anaesthetic and immune function. Curr Opin Anaesthesiol 2001; 14: 685-91.

16 Keblet $H$. Multimodal approach to control postoperative pathophysiology and rehabilitation. Br J Anaesth 1997; 78: 606-17.

17 Carli F. Perioperative factors influencing surgical morbidity: what the anesthesiologist needs to know. Can J Anesth 1999; 46: R70-4.

18 Chrousos GP. The role of stress and the hypothalamicpituitary-adrenal axis in the pathogenesis of the metabolic syndrome: neuro-endocrine and target tissue-related causes. Inter J Obes 2000; 24(Suppl 2): S50-5.

19 Collins TC, Daley J, Henderson WH, Khuri SF. Risk factors for prolonged length of stay after major elective surgery. Ann Surg 1999; 230: 251-9.

20 Keblet $H$. Manipulation of the metabolic response in clinical practice. World J Surg 2000; 24: 690-5.

21 Galley HF, DiMatteo MA, Webster NR.

Immunomodulation by anaesthetic, sedative and analgesic agents: does it matter? Intensive Care Med 2000; 26: 267-74.

22 Gilliland HE, Armstrong MA, Carabine U, McMurray TJ. The choice of anesthetic maintenance technique influences the antiinflammatory cytokine response to abdominal surgery. Anesth Analg 1997; 85: 1394-8.

23 Marana R, Caruana P, Muzii L, Catalano GF, Mancuso $S$. Operative laparoscopy for ovarian cysts excision versus aspiration. J Reprod Med 1996; 41: 435-8.

24 Miura $\Upsilon$, Mackensen B, Nellgrd B, et al. Effects of isoflurane, ketamine, and fentanyl/N2O on concentra- 
tions of brain and plasma catecholamines during nearcomplete cerebral ischemia in the rat. Anesth Analg 1999; 88: 787-92.

25 Goto $\Upsilon$, Ho SL, McAdoo J, et al. General versus regional anaesthesia for cataract surgery: effects on neutrophil apoptosis and postoperative pro-inflammatory state. Eur J Anaesth 2000; 17: 474-80.

26 Frankenfield D, Cooney RN, Smith S, Rowe WA, Bessey $P Q$. Age-related differences in the metabolic response to injury. J Trauma 2000; 48: 49-57.

27 Mostafa G, Huynh T, Sing RF, Miles WS, Norton J, Thomason $M H$. Gender-related outcomes in trauma. J Trauma 2002; 53: 430-5.

28 McCarty Pastores S, Hasko G, Vizi ES, Kvetan V. Cytokine production and its manipulation by vasoactive drugs. New Horiz 1996; 4: 252-64.

29 Van den Berghe $G$, de Zegher F. Anterior pituitary function during critical illness and dopamine treatment. Crit Care Med 1996; 24: 1580-90.

30 Carli F, Bennett GJ. Pain and postoperative recovery. Anesthesiology 95: 573-4.

31 Halter JB, Pflug AE, Porte D. Mechanism of plasma catecholamine increases during surgical stress in man. J Clin Endocrinol Metab 1977; 45: 936-44.

32 Shintani F, Kanba S, Nakaki T, et al. Interleukin-1 beta augments release of norepinephrine, dopamine and serotonine in rat anterior hypothalamus. J Neurosci 1993; 13: 3574-81.

33 Traynor C, Hall GM. Endocrine and metabolic changes during surgery. Anaesthetic implications. Br J Anaesth 1981; 53: 153-60.

34 Scarborough DE. Cytokine modulation of pituitary hormon secretion. Ann N Y Acad Sci 1990; 594: 169-87.

35 Winter JSD, Gow KW, Perry YS, Greenberg AH. A stimulatory effect of interleukin-1 and adrenocortical cortisol secretion mediated by prostaglandins. Endocrinology 1990; 127: 1904-9.

36 Clevenger CV, Russel DH, Appasamy PM, Prystowsky $M D$. Regulation of interleukin 2-driven T-Lymphocyte proliferation by prolactin. Proc Natl Acad Sci USA 1990; 87: 6460-4. 